\title{
ANALISIS KEMAMPUAN PERAWAT DALAM MELAKUKAN BASIC LIFE SUPPORT PADA PASIEN GAWAT DARURAT DI RSU Dr. WAHIDIN SUDIRO HUSODO MOJOKERTO
}

\author{
(ANALYSIS OF NURSE CAPABILITY IN DOING BASIC LIFE SUPPORT IN \\ EMERGENCY PATIENTS AT \\ Dr.WAHIDIN SUDIRO HUSODO HOSPITAL MOJOKERTO)
}

Lutfi Wahyuni ${ }^{1}$, Agus Haryanto ${ }^{2}$

STIKes Bina Sehat PPNI Mojokerto

Email: $\underline{\text { tff.hidayat@gmail.com }}$

\begin{abstract}
ABSTRAK
Pendahuluan: Basic Life Support merupakan suatu upaya yang harus segera dilakukan oleh sesorang apabila menemukan korban yang mengalami henti jantung atau cardiac arrest, setiap tenaga kesehatan wajib memiliki kemampuan yang tepat dalam memberikan tindakan Basic Life Support (BLS). Menurut Riskesdas tahun 2018 prevalensi untuk penderita penyakit kardiovaskuler di Indonesia sebesar 1,5\%. Sedangkan pada wilayah Jawa Timur menunjukkan prevalensi penderita Penyakit Jantung Koroner pada semua usia sebesar 1,7. Tujuan penelitian ini mengalisis kemampuan perawat melaksanakan BasicLife Support pada pasien Cardiac Arrest. Metodologi: Desain yang digunakan adalah diskriftif analisis.Populasinya adalah seluruh perawat di unit gawat darurat sebanyak 45 perawat. Teknik Sampling yang digunakan adalah total sampling. Variabel yaitu kemampuan perawat dalam melakukan Basic Life Support pada pasien Cardiac Arrest. Instrumen yang digunakan berupa lembar observasi SOP Basic Life Support. Hasil: Dari hasil penelitian sebagian besar responden melakukan tindakanBasic Life Support sesuai SOP sebanyak35 perawat (84.4\%), sedangkan yang tidak sesuai SOP dalam melakukan tindakan Basic Life sebanyak 10 perawat (15.6\%). Diskusi: Basic Life Support dilakukan pada pasien yang mengalami Cardiac Arrest. Perawat di ruang gawat darurat gawat berwenang melakukanBasic Life Support yang meliputi cek kesadaran, bebaskan jalan nafas, pijat jantung dan ventiasi.
\end{abstract}

\section{Kata kunci: Basic Life Support, Cardiac Arrest, Perawat, Kemampuan}

\section{ABSTRACT}

Introduction: Basic Life Support is an effort that must be done immediately by someone if finding victims who experienced cardiac arrest, every health worker must obtained the skilfull ability to provide Basic Life Support (BLS) measures. According to Riskesdas in 2018 the prevalence of cardiovascular disease sufferers in Indonesia is 1.5\%. Whereas in the East Java region showed the prevalence of coronary heart disease sufferers at all ages is 1.7. The purpose of this study is to analyze the ability of nurses to implement Basic Life Support in Cardiac Arrest patients. Method: The design used is descriptive analysis. The population is all nurses in the emergency department as many as 45 nurses. The sampling technique used is total sampling. The variable is the ability of nurses in conducting Basic Life Support in Cardiac Arrest patients. The instrument used an SPO Basic Life Support observation sheet.Result: The results showed, most of the respondents did the Basic Life Support action according to the SPO as many as 35 nurses (84.4\%), while those who were not performingvaccording to the SPO were 10 nurses (15.6\%). Discussion: Basic Life Support is performed on patients who have Cardiac Arrest. Nurses in the emergency room are authorized to conduct Basic Life Support which includes checking consciousness, free airway, cardiac massage, and ventilation.

Keywords: Basic Life Support, Cardiac Arrest, Nurse, Ability 
ISSN Cetak 2303-1433

ISSN Online: 2579-7301

\section{PENDAHULUAN}

Kegawatdaruratan henti jantung atau cardiac arrest adalah suatu suatu keadaan dimana terjadinya penghentian mendadak sirkulasi normal darah ditandai dengan menghilangnya tekanan darah arteri. Pertolongan yang tepat dalam kasus kegawatdaruratan cardiac arrest adalah dengan tindakan Basic Life Support (BLS). (Hardisman, 2014). Basic Life Support (BLS) adalah suatu upaya oksigenasi darurat yang harus dilakukan dengan cepat untuk pennaganan pasien yang mengalami henti jantung dan henti nafas secara mendadak yang disebabkan oleh berbagai keadaan seperti pada korban tenggelam, tersengat listrik, kecelakaan lalu lintas, korban kebakaran, serangan jantung, dan keadaan kegawatdaruratan lainnya. (Bambang et all, 2012)

Tindakan Basic Life Support (BLS) padacardiacarrest sudah sering dilakukan, namun masih ada beberapa prosedur Basic Life Support (BLS) yang kurang sempurna karena masih ada beberapa tindakan yang terlewati.

Menurut data WHO pada tahun 2016,. Penyakit jantung dan stroke menjadi penyebab kematian utama, 15 tahun terakhir ini.(WHO, 2018)

Menurut Riskesdas tahun 2018 prevalensi untuk penderita penyakit kardiovaskulersebesar $1,5 \%$ Sedangkan pada wilayah Jawa Timur menunjukkan prevalensi penderita penyakit jantung coroner pada semua usia sebesar $1,7 \%$. (Riskesdas, 2018). Berdasarkanhasilstudy awal yang dilaksanakan di ruang ICU/ICCU pasien yang mengalami cardiac arrest pada bulan Januari - Desember tahun 2018 sebanyak 189 pasien, sedangkan jumlah pasien cardiac arrest di IGDpada bulan Janurai- Desember 2018 sebanyak 100 pasien.

Berdasarkan hasil penelitian Pramita \&Maria (2014) yang dilakukan di ruang ICU rumah sakit Jakarta tentang pengetahuan perawat terhadap basic life support pada pasien henti jantung di dapatkan dari 48 responden, sebanyak 24 berpengetahuan baik tentang basic life support, sedangkanyang berpengetahuan kurang sebanyak 24 responden.

Tindakan Basic Life Support (BLS) pada kasus kegawatdaruratan henti jantung harus dilakukan dengan cepat dan tepat. Keterlambatan dan kesalahan dalam melakukan tindakan gawat darurat dapat menimbulkan efek yang sangat fatal dan tidak dapat diperbaiki pada tindakan selanjutnya. Sehinggasetiap tenaga kesehatan terutama perawat harus memiliki kemampuan yangbaikdansesuai SOPtentang Basic Life Support (BLS) . (Mawar \& Sugianto, 2013)

Pemberian tindakan Basic Life Support (BLS) untuk menangani cardiac arrest dibutuhkan kemampuan perawat dalam melakukan tindakan Basic Life Support (BLS) yang dapat diperoleh melalui proses pembelajaran, atau melalui pelatihan khusus serta dapat diperoleh melalui seminar agar dapat diaplikasikansesuai SOP tindakan Basic Life Support (BLS). (Wiliastuti, Anna, \& Mirwanti, 2018)

Berdasarkan fenomena yang terjadi makaperludilakukan“AnalisisKemampuan Perawat Dalam Melakukan Basic Life Support Pada Pasien Cardiac ArrestDi Rsu Dr. Wahidin Sudiro Husodo Kota Mojokerto"

\section{BAHAN DAN METODE}

Desain penelitian ini deskriptif analisis. Teknik sampling menggunakan total sampling atau sampling jenuh. Populasi dalam penelitian ini adalah seluruh perawat di unit/ruang gawat darurat gawat di RSU DR. Wahidin Sudiro Husodo Kota Mojokerto sebanyak 45 perawat. Pengambilan data kemampuan perawat dalam melakukan tindakan Basic Life Support dengan menggunakan lembar observasi SOPBasic Life Support (BLS). Variabel penelitian, Kemampuan perawat dalam melakukan Basic Life Support (BLS). Waktu penelitian bulan Maret-Agustus 2019 
ISSN Cetak 2303-1433

ISSN Online: 2579-7301

HASIL

Tabel 1.Data Umum Responden Di RuangGawatdarurat

\begin{tabular}{lllll}
\hline No & Data Umum & \multicolumn{1}{c}{ Ket } & F & \multicolumn{1}{c}{$\%$} \\
\hline 1. & Jeniskelamin & Laki-laki & 27 & 60,0 \\
& & Perempuan & 18 & 40,0 \\
2.. & Usia & $<30$ tahun & 9 & 20,0 \\
& & $30-45$ tahun & 36 & 80,0 \\
\multirow{2}{*}{ 3. } & \multirow{2}{*}{ Masa Kerja } & $>45$ tahun & 0 & 0 \\
& & $<3$ tahun & 4 & 8,9 \\
& & $3-5$ tahun & 15 & 33,3 \\
4. & Pendidikan & $>5$ tahun & 26 & 57,8 \\
& & D3 Kep & 10 & 22,2 \\
5. & Pelatihan & S1 Kep,Ns & 35 & 77,8 \\
& & BTCLS & 45 & 100 \\
\hline
\end{tabular}

Sumber:Data Primer

Berdasarkan tabel1 perawat laki-laki sebanyak 27orang $(60 \%)$ dan perempuan sebanyak 18 orang (40\%) dengan usia sebagian besar perawat30-45tahun sebanyak 36 orang $(80 \%)$. Berdasarkan masa kerja di dapatkan bahwa perawat bekerja $>5$ tahun yaitu26 $(57,8 \%)$. dengan tingkat pendidikan sebagian besar perawat berpendidikan S1 Keperawatan+Ners yaitu sebanyak35 orang (77.8\%). Selain itu semua perawat telah mengikuti pelatihan BTCLS

Tabel 2 Analisis Kemampuan Perawat Dalam Melakukan Basic Life Support Pada Pasien Cardiac Arrest

\begin{tabular}{|c|c|c|c|}
\hline No & Kriteria & Frekuensi & Presentase (\%) \\
\hline 1. & $\begin{array}{l}\text { Sesuai } \\
\text { SOP }\end{array}$ & 38 & $84,4 \%$ \\
\hline 2. & $\begin{array}{l}\text { Tidak } \\
\text { sesuai SOP }\end{array}$ & 7 & $15,6 \%$ \\
\hline
\end{tabular}

\begin{tabular}{ccc}
\hline Total & 45 & $100 \%$ \\
\hline
\end{tabular}

Sumber: Data Primer

Berdasarkan tabel 2 di dapatkan hasil sebanyak 38 responden $(84,4 \%)$ melakukan tindakan Basic Life Support sesuai SOP dan 7 responden $(15,6 \%)$ melakukan tindakan Basic Life Support tidak sesuai SOP

\section{PEMBAHASAN}

Hasil penelitian di peroleh data bahwa responden yang melakukan tindakan basic life support sesuai SOP sebanyak 38 responden $(84,4 \%)$ dan sebanyak 6 responden $(15,6 \%)$ melakukan tindakan Basic Life Support tidak sesuai SOP. Berdasarkan hasil analisis SOP Basic Life Support yang terdiri dari 8 langkah di dapatkan pada langkah 1 ( Proteksi Diri) 1 responden tidak melakukan sesuai SOP yaitu tidak mencuci tangan sebelum tindakan kepasien, pada langkah 4 ( Circulasi) 3 responden tidak melakukan pengecekan cirkulasi secara lengkap dan kurang tepat melakukan CPR, pada langkah 8 (Cek tanda ROSC, Response Of Spontaneous Circulation) 2 responden kurang tepat melakukan obsevasi nadi karotis sambal melihat pergerakan dada jika pasien sudah ada respon atau pergerakkan spontan selama 5-10 detik setiap 5 siklus.

Menurut Notoadmodjo (2010) kemampuan melakukan suatu tindakan merupakan aplikasi dari pengetahuan seseorang sehingga tingkat kemampuan seseorang berkaitan faktor-faktor yang mempengaruhi seperti usia, tingkat pendidikan dan pengalaman. Seiring dengan bertambahnya usia akan terjadi perubahan secara fisik dan psikologis. Semakin cukup usia,maka akan semakin matangdalam proses berfikir dan bekerja (Notoatmodjo, 2010). Masa kerja dapat mempengaruhi kemampuan seseorang dalam bertindak, semakin lama seseorang bekerja maka akan semakin banyak pengalamanbaru yang didapat hal tersebut menyebabkan kemampuan seseorang akan semakin baik pula (Ranupendoyo \& Saud, 2005). Tingkat Pendidikan mempengaruhi pola pikir dan kemampuan seseorang, diharapkan semakin tinggi Pendidikan sesorang di harapkan semakin baik pengetahuan sesorang. Sehingga dapat memudahkan dalam menerima dan menyerap hal baru. (Notoatmodjo, 2010). Menurut International Nurse Training Center (INTC, 2009) mengungkapkan bahwa kemampuan perawat dalam melaksanakan pelayanangawat darurat terkait dengan pernah tidaknya mengikuti pelatihan tentang penanganan gawat darurat serta pelatihan BTCLS sebagai kompetensi dasar penanggulangan penderita gawat darurat (PPGD). 
ISSN Cetak 2303-1433

ISSN Online: 2579-7301

Menurut peneliti kemampuan perawat dalam melakukan Basic Life Support pada pasien cardiac arrest yang tidak sesuai SOP dipengaruhi oleh faktor usia, perawat yang berusia < 30 tahun cenderung melakukan tindakanbasiclife support yang tidak sesuai dengan SOP. Hal tersebut dikarenakanseiringbertambahnya usia maka akan semakin matang dalam proses berfikir dan bekerja serta bertambah pula pengalaman yang didapatkan dan hal tersebut dapat mempengaruhi kemampuan dalam melakukan tindakan Basic Life Support. Responden dengan usia 30-45 tahun cenderung mampu melakukan tindakan basic life support yan sesuai dengan SOP. Hal ini dikarenakan semakin cukup usia maka semakin matang dalam proses berfikir. Selain itu perawat yang melakukan tindakan basic life support yang tidak sesuai SOP juga dipengaruhi oleh masa kerja, perawat yang masa kerjanya kurang dari 3 tahun cenderung melakukan tindakan Basic Life Support tidak sesuai dengan SOP hal tersebut disebabkan oleh perawat yang masa kerjanya lama memperoleh pengalaman yang lebih yang didapat selama masa kerjanya.Perawat yang masa kerjanya lebih dari 5 tahun mampu melakukan tindakan baic life support yang sesuai dengan SOP. Hal ini dikarenakan perawat yang telah bekerja lebih dari 5 tahun telah melakukan tindakan basic life support berulang kali, sehingga bertambah pula pengalaman yang telah didapat.

Menurut peneliti kemampuan responden dalam melakukan tindakan Basic Life Support yang sesuai SOP dipengaruhi jenis kelamin. perawat yang berjenis kelamin perempuan maupun laki-laki mampu melakukan tindakan basic life support yang sesuai SOP,hal ini menunjukkan tidak adaperbedaankemampuan anatar perawat yangberjenis kelamin laki-laki maupun perempuan.Perawat laki-laki dan perempuan sama mampu melakukan tindakan basic life support sesuai dengan SOP. Kemampuan melakukan tindakan Basic Life Support yang sesuai SOP juga dipengaruhi oleh tingkatpendidikan karena responden yang telah menjalani pendidikan baik D3 Keperawatan, S1 Keperawatan, dan Ners semua jenjang pendidikan tersebut telah melakukan pelatihan Basic Trauma Cardiac Life Support sehingga telah mengetahui apa saja prosedur dalam melakukan tindakan Basic Life Support.Selain telah mendapat pelatihan Basic Trauma Cardiac Life Support perawat yang bertugas di ruang IGD dan ICU/ICCU RSU DR. Wahidin Sudiro Husodo Kota Mojokerto juga mendapatkan pelatihan tambahan lainnya seperti pelatihan ACLS.Basic Life Support dilakukan pada pasien yang mengalami Cardiac Arrest. Perawat di unit/ruang gawat darurat berwenang melakukan Basic Life Support yang meliputi cek kesadaran, bebaskan jalan nafas, pijat jantung dan ventilasi. Basic Life Support di lakukan maksimal 5 siklus atau sampai ada ROSC. Basic Life Support juga di pengaruhi oleh ketrampilan perawat, fasilitas yang ada di Rumah sakit dan pelatihan yang di ikuti oleh perawat. Dalam pemberian tindakan Basic Life Support harus dilakukan dengan memperhatikan karakteristik high quality Basic Life Support yang meliputi pemberia nkompresi dada dengan Rate dan Depth yang memadai. Rate yang dianjurkan yaitu pada rentang $100-$ $120 \mathrm{kali} / \mathrm{menit}$ serta Depth yang dianjurkan yaitu pada rentang $2-2,4$ inchi $(5-6 \mathrm{~cm})$. Selain itu complete recoil pada tiap akhir kompresi, minimal interruptions dan mencegah pemberian ventilasi yang berlebihan juga merupakan komponen dalam high quality

\section{SIMPULAN DAN SARAN SIMPULAN}

Kemampuan perawat yang bertugas di ruangan IGD dan ICU/ICCU dalam melakukan basic life support pada pasien cardiac arrest di RSU DR. Wahidin Sudiro Husodo Kota Mojokerto menunjukkan bahwa sebagian besar perawat mampu melakukan tindakan basic life support yang sesuai dengan SOP. Hal ini dikarenakan karna seluruh perawat telah mendapatkan pelatihan BTCLS dan sebagian besar perawat telah bekerja lebih dari 5 tahun 
ISSN Cetak 2303-1433

ISSN Online: 2579-7301

\section{SARAN}

1. Bagi Perawat

Diharapkan penelitian ini menjadi bahan masukan bagi perawat untuk dapat terus meningkatkan kemampuan dalam memberikan tindakan terhadap pasien khusunya pada penanganan cardiac arrest Bagi perawat yang belum sesuai dengan SOP agar lebih meningkatkan kemampuan melakukan tindakan Basic Life Support dengan cara mereview kembali materi tentang Basic Life Support.

2. Bagi Rumah Sakit

Diharapkan rumah sakit dapat menjadwal kembali untuk pelatihan gawat darurat.

3. Bagi Instansi Pendidikan

Penelitian ini dapat digunakan untuk tambahan referensi dan wawasan bagi mahasiswa dalam penanganan gawat darurat pasien cardiac arrest

4. Bagi Peneliti Selanjutnya

Peneliti selanjutnya dapat menggali lebih dalam lagi dengan menambah variabelpengetahuan atau edukasi, desain penelitian dengan eksperimen atau korelasi, dan menambah jumlah responden.

\section{DAFTAR PUSTAKA}

American Heart Association. (2015). FOKUS UTAMA Pembaruan Pedoman American Heart Association 2015 untuk CPR dan ECC. Medicina Intensiva.

https://doi.org/10.1016/S0210-

5691(06)74511-9diakseps pada 16 November 2018

Annamma, J. (2014). Buku Ajar Clinical Nursing Procedures Jilid 2. Jakarta: BINARUPA AKSARA.

Arikunto, S. (2012). Prosedur Penelitian Suatu PendekatanPraktis. Jakarta: PT. Rineka Cipta.

Bambang, S., putu, moda, A., Agus, S., arto, yuwono, S., \& Murdani, A. (2012). EIMED PAPDI Kegawatdaruratan Penyakit Dalam (Emergency In Internal Medicine). Jakarta: Interna Publishing.
Beni, A. S. (2008). METODE PENELITIAN. Bandung: CV. Pustaka Setia.

Boswick, J. A. (2012). Perawatan Gawat Darurat. (P. Andrianto, Ed.). Jakarta: EGC.

Budiman, \& Agus, R. (2013). Kapita Selekta Kuisioner Pengetahuan dan Sikap dalam Penelitian Kesehatan. Jakarta: Salemba Medika.

Departemen Pendidikan Indonesia,. (2016)Kamus Besar Bahasa Indonesia. Jakarta:Balai Pustaka

Hardisman. (2014). Gawat Darurat Medis Praktis. Yogyakarta: Gosyen Publishing.

Hidayat, A. A. (2010). Metode Penelitian Kesehatan Paradigma Kuantitatif. Jakarta: Health Book.

Hidayat, A. A. (2012). Riset Keperawatan dan Teknik Penulisan Ilmiah (2nd ed.). Jakarta: Salemba Medika.

Huon, G., Keith, D., John, M., \&Iain, S. (2005). Lecture Notes:Kardiologi (4th ed.). Jakarta: Erlangga.

International Nurse Training Center (INTC). (2009). Pelatihan Basic Trauma Cardiac Life Support (BTCLS). www.intc.or.id

Jeffrey M, S. (2012). MASTER PLAN Kedaruratan Medik. (L. Saputra, Ed.). Tangerang: BINARUPA AKSARA.

Mansjoer, A., \& Sudoyono, A. W. (2010). Resusitusi Jantung Paru.Buku Ajar Ilmu Penyakit Dalam. (V). Jakarta: Interna Publishing.

Mardalis. (2010). Metode Penelitian Studi Pendekatan Proposal (1st ed.). Jakarta: Bumi Aksara.

Mawar, K., \& Sugianto, S. (2013). SURVEY TINGKAT PENGETAHUAN PERAWAT TENTANG BANTUAN, 18.http//lib.ui.ac.id/file?file=pdf diakses pada 14 Desember 2018

Notoatmodjo, S. (2010). Metodologi Penelitian Kesehatan. Jakarta: Rineka Cipta.

Notoatmodjo, S. (2012). METODOLOGI PENELITIAN KESEHATAN. Jakarta: Rineka Cipta.

Nugroho, T., Putri, B. T., \& Kirana, D. (2016). Teori Asuhan Keperawatn 
ISSN Cetak 2303-1433

Gawat Darurat. y: Nuha Medika.

Nursalam. (2015). MetodolohiPenelitian Ilmu Keperawatan:Pendekatan Praktis (4th ed.). Jakarta: Salemba Medika.

Stephen, \& Timothy. (2009). Teori Organisasi:Struktur, Desain, dan Aplikasi (ketiga). Jakarta: Arcan.

Pramita, A. C., \& Maria, R. (2014).PENGETAHUAN PERAWAT TENTANG PEMBERIAN BANTUAN HIDUP DASAR PADA PASIEN HENTI JANTUNG DI RUANG INTENSIVE CARE RUMAH SAKIT DI JAKARTA, 1-

9.http://lib.ui.ac.id/naskahringkas/201609/S57572-

Aam\%20Citrida\%20Pramitadiakses pada 11 November 2018

Ranupendoyo, \& Saud. (2005). Manajemen Personalia. Yogyakarta: Pustaka Birawan.

Riskesdas. (2013). BADAN PENELITIAN DAN PENGEMBANGAN KESEHATAN KEMENTERIAN KESEHATAN RI TAHUN 2013.

Riskesdas. (2018). Hasil Utama RISKESDAS 2018 Kementerian Kesehatan Badan Penelitian dan Pengembangan Kesehatan.

Sesrianty, V. (2018). Hubungan Pendidikan Dan Masa Kerja Dengan Keterampilan Perawat Melakukan Tindakan Bantuan Hidup Dasar. Kesehatan Perintis, 5, 165.http://jurnal.stikesperintis.ac.iddiak ses pada 23 janari 2019

Setiadi. (2013). Konsep dan Praktek Penulisan Riset Keperawatan (2nd ed.). Yogyakarta: Graha Ilmu.

Sudiharto, \& Sartono. (2011). BASIC TRAUMA CARDIAC LIFE SUPPORT. Jakarta:CV Sagung Seto.

Sutawijaya, R. B. (2009). GAWAT DARURAT Panduan Kesehatan Wajib di Rumah Anda. Yogyakarta: Aulia Publishing.

WHO. (2018). The top 10 causes of death. Retrieved January 23, 2019, from https://www.who.int/news-room/factsheets/detail/the-top-10-causes-ofdeathdiakses pada 23 Januari 2019

Wiliastuti, U. N., Anna, A., \& Mirwanti, R. (2018). Pengetahuan tim reaksi cepat tentang bantuan hidup dasar 1 . Keperawatan Komprehensif, 4, 7785.http://lib.unpad.ac.iddiakses pada 14 Desember 2018 